\title{
Proceeding Paper \\ Colorimetric Determination of Nitrate after Reduction to Nitrite in a Paper-Based Dip Strip ${ }^{+}$
}

\author{
Amer Charbaji *(D), Hojat Heidari-Bafroui (D), Nasim Rahmani, Constantine Anagnostopoulos and \\ Mohammad Faghri *
}

Citation: Charbaji, A.;

Heidari-Bafroui, H.; Rahmani, N.; Anagnostopoulos, C.; Faghri, M. Colorimetric Determination of Nitrate after Reduction to Nitrite in a Paper-Based Dip Strip. Chem. Proc. 2021, 5, 9. https://doi.org/10.3390/ CSAC2021-10459

Academic Editor: Manel del Valle

Published: 30 June 2021

Publisher's Note: MDPI stays neutral with regard to jurisdictional claims in published maps and institutional affiliations.
Microfluidics Laboratory, Department of Mechanical, Industrial and Systems Engineering, University of Rhode Island, 2 East Alumni Avenue, Kingston, RI 02881, USA; h_heidari@uri.edu (H.H.-B.); nara7@uri.edu (N.R.); anagnostopoulos@uri.edu (C.A.)

* Correspondence: charbaji@uri.edu (A.C.); faghrim@uri.edu (M.F.)

+ Presented at the 1st International Electronic Conference on Chemical Sensors and Analytical Chemistry, 1-15 July 2021; Available online: https:/ /csac2021.sciforum.net/.

\begin{abstract}
Paper-based microfluidic technology is a relatively new field of research that provides low-cost platforms and sensors for point-of-care diagnostics. While the majority of research in this field has been for biomedical applications, more and more paper-based devices and platforms are being designed and developed for environmental applications, such as water quality monitoring and assessment. One such application is the detection of nitrate in water samples. Colorimetric detection of nitrate by paper-based devices using the Griess assay requires the reduction of nitrate to nitrite before undergoing the reaction. In this paper, we measured the performance of a paper-based dip strip for detecting nitrate and nitrite by calculating its limit of detection and limit of quantification. We also calculated the reduction efficiency of vanadium (III) chloride in the dip strip for detecting nitrate. Our results show that the reduction time of nitrate via vanadium (III) chloride is much longer than that when using zinc microparticles. Our results also show that the performance of the dip strip using vanadium (III) chloride for nitrate detection is not as good as more intricate paper-based devices that have a separate reaction zone with zinc microparticles. The limits of detection and quantification calculated were 3.352 and $7.437 \mathrm{ppm}$, and the nitrate reduction efficiency varied over the range of nitrate concentrations tested.
\end{abstract}

Keywords: nitrate reduction; zinc microparticles; vanadium (III) chloride; materials for chemical sensing; nitrate detection; Griess reaction; colorimetric assay; paper-based devices; paper microfluidics; point-of-care diagnostics

\section{Introduction}

Paper-based microfluidic technology has been gaining a lot of attention over the past several years for the many advantages it provides. Most importantly, paper-based microfluidic technology allows the development of low-cost, portable and easy-to-use devices and sensors that can be easily disposed of. These devices can also provide qualitative or quantitative results and data at the point of care without the need for specialized equipment or power sources. Several paper-based devices have been developed for various applications, such as for water analysis [1-4], biomedical applications [5,6], food analysis [7-10], soil analysis [11] and many other miscellaneous applications [12-15]. The field of paper-based microfluidics is expected to continue garnering greater attention as more applications are sought after or the performance improved for the ones already developed [16].

Paper-based devices are generally made up of several different sections that serve different purposes. While more complex devices may include valves and actuators to manipulate fluids and perform multistep reactions $[17,18]$, simpler devices generally include a sample port, transport channels, reactions zones and a detection zone [19]. The majority of paper-based devices use colorimetric detection since it is the simplest technique 
to produce a quantifiable signal $[20,21]$. Properties of the material used in paper-based devices influence assay performance and have a substantial impact on the development of paper-based sensors [22]. Therefore, proper material selection and optimization is critical to enhancing the performance of assays in paper-based devices [23]. This is usually an iterative and an ongoing process to learn and adapt different advancements in the field of paper-based technology to check for the possibility of improving the output and performance of paper-based sensors. An example is the selection of a suitable reducing agent to be used in a paper-based device meant for detecting nitrate in water.

Nitrate is part of the nitrogen cycle [24] and is an essential nutrient needed for plant growth; however, it plays a significant role in water nutrient pollution when present in excessive amounts $[25,26]$. Nitrate is also the most stable form of nitrogen in oxygenated systems, and all other forms of nitrogen-containing compounds can become a source for it $[27,28]$. Ingesting nitrate has been linked to colorectal cancer, thyroid disease and central nervous system birth defects [29]. Therefore, it is important to measure nitrate levels in water for environmental monitoring purposes and to ensure its safety for consumption. Different techniques are readily available to measure nitrate concentrations in water but are either costly, time-consuming or may require trained personnel [30,31]. Several paper-based sensors have been developed for the rapid and inexpensive detection of nitrate in water, food and human saliva, and their limits of detection (LOD) and limits of quantification (LOQ) are given in Table 1.

Table 1. Performance of paper-based sensors developed for detecting nitrate in different media.

\begin{tabular}{cccc}
\hline Reference & Media & LOD $(\mathbf{p p m})$ & LOQ $(\mathbf{p p m})$ \\
\hline$[32]$ & Water & 0.533 & 1.765 \\
{$[33]$} & Water & 1.178 & 2.976 \\
{$[9]$} & Food Sample & 3.6 & 12 \\
{$[34]$} & Food Sample & 0.4 & $\mathrm{NA}^{1}$ \\
{$[35]$} & Food Sample & 0.4 & 1.4 \\
{$[36]$} & Human Saliva & 4.96 & 16.74 \\
\hline
\end{tabular}

${ }^{1} \mathrm{NA}$, not available.

All of the paper-based devices developed thus far for measuring nitrate levels have used the Griess assay for detection since it is the most commonly used spectrophotometric method for quantifying concentrations of nitrate and nitrite [37,38]. However, this assay is specific to nitrite molecules and, therefore, nitrate molecules have to be reduced to nitrite first before detection. There are several different reducing agents that can reduce nitrate to nitrite, such as cadmium, copperized cadmium, zinc, nitrate reductase, irradiation by ultraviolet light, hydrazine sulfate, titanium (III) chloride, vanadium (III), hydroxylamine, tin chloride or ascorbic acid $[36,39,40]$. Some of these reducing agents are not suitable for use in paper-based devices, while others have been tested and used in this type of sensors.

Nitrate reductase, irradiation by ultraviolet and hydrazine require lengthy reduction times [41], which may not be suitable for paper-based sensors due to concerns of sample evaporation. Titanium (III) chloride is violet in color and absorbs light in the same range as the azo dye product of the Griess assay [41]. Ferreira et al. [36] tested tin chloride, hydroxylamine, ascorbic acid and zinc microparticles. They used zinc microparticles in their paper-based nitrate sensor since the other agents tested did not extensively reduce nitrate to nitrite. Experimental results by Jayawardane et al. [33] showed that cadmium and zinc microparticles produced similar results for nitrate reduction in their paper-based device. They opted for zinc microparticles due to the higher toxicity of cadmium. Thongkam et al. [35] developed a very simple paper-based device for measuring nitrate and nitrite concentrations in food samples, and they used vanadium (III) chloride to reduce nitrate before detection.

We had previously developed a sensitive paper-based nitrate sensor by testing different device architectures and optimizing the different components of the device [32]. The final device adopted a folding architecture with part of the detection chemistry immobilized 
at the detection zone. This improved the quality and uniformity of the signal developed. The device also incorporated a new composite material made-up of zinc microparticles and cellulose fibers to enhance nitrate reduction. A nitrate conversion efficiency of $27 \%$ was achieved using this new composite material called Zinculose [42]. However, the results obtained by Thongkam et al. [35] for nitrate detection in food samples by using vanadium (III) chloride as a reducing agent are very promising. In this paper, we measure the performance of a dip strip using vanadium (III) chloride for reducing nitrate by calculating its limits of detection and quantifications. We also calculate the nitrate reduction efficiency of vanadium (III) chloride and compare the results to those obtained when using Zinculose.

\section{Methods}

Thongkam et al. [35] studied the effect of the different parameters on nitrate detection. They tested different concentrations of sulfanilic acid and N-(1-Naphthyl)ethylenediamine dihydrochloride used in the Griess assay for detection. They also examined the effect of different concentrations of vanadium (III) chloride and reaction times on the intensity of the color produced in the detection zone. In this paper, we use the optimum concentrations they have found when preparing the reagents to be used in our experiments.

\subsection{Materials}

The items below were used in preparing and running the experiments presented in this paper. Whatman grade 1 filter paper (GE Healthcare Whatman 1-1001824), backing cards (DCN Dx MIBA-050), sulfanilamide (98\%, Alfa Aesar-A1300136), N-(1-Naphthyl)ethylenediamine dihydrochloride (Alfa Aesar-J6321414), hydrochloric acid (Fisher Chemical-A142-212), sodium nitrate ( $\geq 99.5 \%$, Honeywell Fluka-31440), sodium nitrite ( $\geq 99 \%$, Honeywell Fluka31443) and ASTM Type 1 deionized water (resistivity $>18 \mathrm{M} \Omega / \mathrm{cm}$, LabChem-LC267405).

\subsection{Methods}

Strips $1 \times 8 \mathrm{~cm}$ were cut out from a $30 \times 8 \mathrm{~cm}$ backing card using a guillotine paper cutter. Three circles, $6 \mathrm{~mm}$ in diameter each, were punched out using a tissue biopsy from the Whatman filter paper and stuck onto the backing card, Figures 1 and S1.

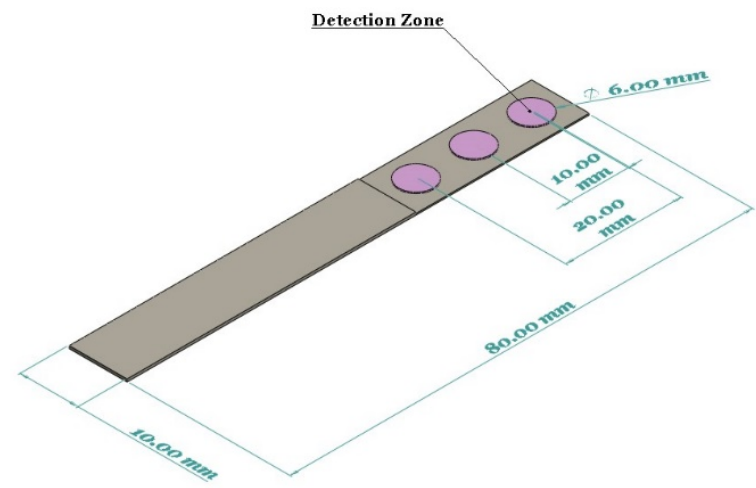

(a)

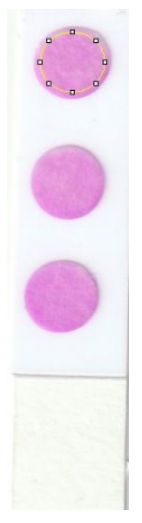

(b)

Figure 1. (a) Schematic showing the components and dimensions of the dip strip used. (b) The yellow circle shows the color analysis zone used in ImageJ to quantify the color intensity of one of the detection zones; the diameter of the circle is about 125 pixels, which is approximately $5.3 \mathrm{~mm}$.

Nitrate and nitrite solutions at concentrations of $1000 \mathrm{ppm}$ were freshly prepared on the day of testing by dissolving the required amount of nitrate or nitrite salt in deionized water. These solutions were then diluted using deionized water into the following concentrations $0.5,1,2.5,5,10,20$ and $40 \mathrm{ppm}$. We followed the procedure outlined by Thongkam et al. [35] in preparing the detection chemistry for nitrate and nitrite. For nitrite detection, 
the solution was called reagent " $\mathrm{A}$ " and consisted of equal parts (1:1 ratio) volume of sulfanilic acid and NED solution. For nitrate detection, the solution used was called reagent " $B$ " and consisted of equal parts (1:1:1 ratio) volume of the above sulfanilic acid, NED solution and the reducing reagent solution. The sulfanilic acid used in reagents " $\mathrm{A}$ " and "B" was prepared by dissolving $0.1 \mathrm{~g}$ of sulfanilamide in $100 \mathrm{~mL}$ of $2 \mathrm{~mol} \mathrm{~L}^{-1}$ hydrochloric acid. The NED solution used in reagents " $\mathrm{A}$ " and " $\mathrm{B}$ " was prepared by dissolving $0.1 \mathrm{~g}$ of N-(1-Naphthyl)ethylenediamine dihydrochloride in $100 \mathrm{~mL}$ of deionized water. The reducing reagent solution used in reagent " $\mathrm{B}$ " was prepared by dissolving $3 \mathrm{~g}$ of vanadium (III) chloride in $100 \mathrm{~mL}$ of $6 \mathrm{~mol} \mathrm{~L}^{-1}$ hydrochloric acid. $2 \mu \mathrm{L}$ of reagent $\mathrm{A}$ or $\mathrm{B}$ was pipetted onto each circle and allowed to air-dry for at least $30 \mathrm{~min}$, Figure S2. Each dip strip was then submerged into the appropriate nitrate or nitrite solution for $1 \mathrm{~s}$, shaken to remove excess fluid and then scanned using a desktop scanner (Canon TS6020) at a resolution of 600 DPI. The nitrate dip strips were scanned after $10 \mathrm{~min}$, and the nitrite dip strips were scanned after $5 \mathrm{~min}$ following the optimized scan times previously found by Thongkam et al. [35]. The detection zones were analyzed using ImageJ in RGB mode, similar to how they analyzed their results. We have previously shown that the green component of the measured color intensity shows the largest difference in value over the concentration of nitrate or nitrite for paper-based devices using the Griess assay [43]. Therefore, the data for the different color intensities were provided in the supplementary file, Tables S1-S4. A MATLAB code was used to fit the data to an exponential decay function of the form $\mathrm{y}=\mathrm{a} \times \exp (-\mathrm{x} / \mathrm{b})+\mathrm{c}$, and the symbolic toolbox was used to calculate the limits of detection and quantification. The limits of detection and quantification were obtained by finding the analyte concentrations corresponding to $y_{L O D}$ or $y_{L O Q}$ on the calibration curves developed. $y_{L O D}$ or $y_{L O Q}$ were calculated using the following equations [44]:

$$
\begin{gathered}
y_{L O D}=\bar{y}_{B}-3 \sigma_{B} \\
y_{L O Q}=\bar{y}_{B}-10 \sigma_{B}
\end{gathered}
$$

where $\bar{y}_{B}$ corresponds to the mean color intensity of the blank solution $(0 \mathrm{ppm})$ and $\sigma_{B}$ is its respective standard deviation.

\section{Results and Discussion}

The detection zones of the nitrate dip strips showed little to no color change after $10 \mathrm{~min}$, Figure S3, but color started to form after a much longer wait time, so the dip strips were scanned after $1 \mathrm{~h}$ as well, Figure S4. The following section shows the results obtained for the nitrate and nitrite dip strips.

\subsection{Nitrate and Nitrite Analysis}

Figure 2 shows the calibration curves developed for the detection of nitrate in deionized water after a reaction time of $10 \mathrm{~min}$ and $1 \mathrm{~h}$. The limits of detection and quantification for nitrate after $10 \mathrm{~min}$ are 37.03 and $121 \mathrm{ppm}$, respectively. The limits of detection and quantification for nitrate after $1 \mathrm{~h}$ are 3.352 and $7.437 \mathrm{ppm}$, respectively.

Figure 3 shows the calibration curves developed for the detection of nitrite in deionized water after a reaction time of $5 \mathrm{~min}$ and $1 \mathrm{~h}$. The limits of detection and quantification for nitrite after $5 \mathrm{~min}$ are 0.522 and $0.854 \mathrm{ppm}$, respectively. The limits of detection and quantification for nitrite after $1 \mathrm{~h}$ are 0.889 and $1.823 \mathrm{ppm}$, respectively. 


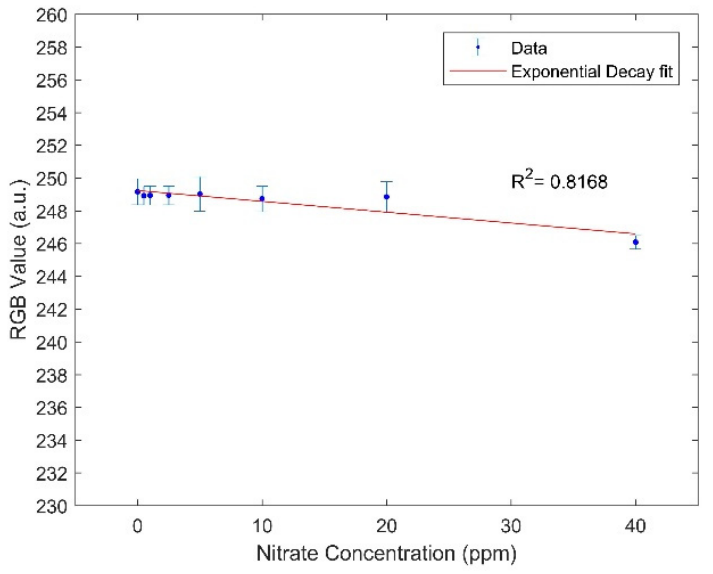

(a)

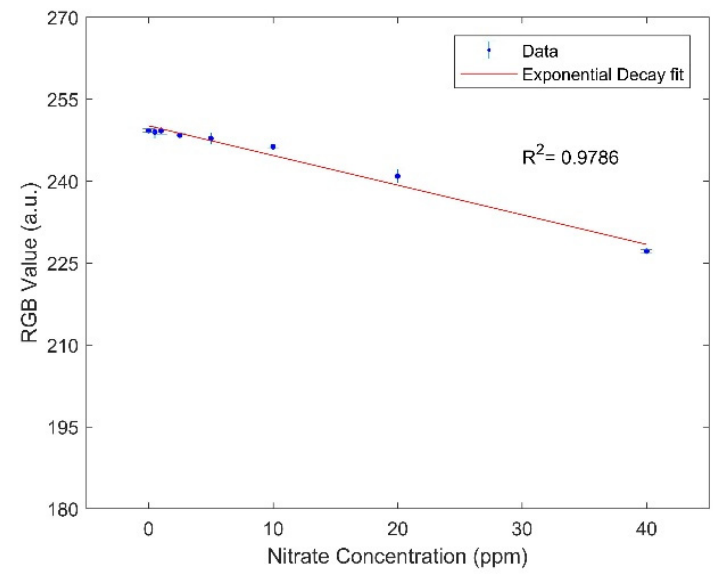

(b)

Figure 2. (a) An exponential decay calibration curve in the form $y=a \times \exp (-x / b)+c$, where $a=2741, b=41,430$ and $c=-2492$ was established for nitrate after a reaction time of $10 \mathrm{~min}$. (b) An exponential decay calibration curve in the form $\mathrm{y}=\mathrm{a} \times \exp (-\mathrm{x} / \mathrm{b})+\mathrm{c}$, where $\mathrm{a}=80,230, \mathrm{~b}=147,700$ and $\mathrm{c}=-79,980$ was established for nitrate after a reaction time of $1 \mathrm{~h}$. The error bars represent the standard deviation.

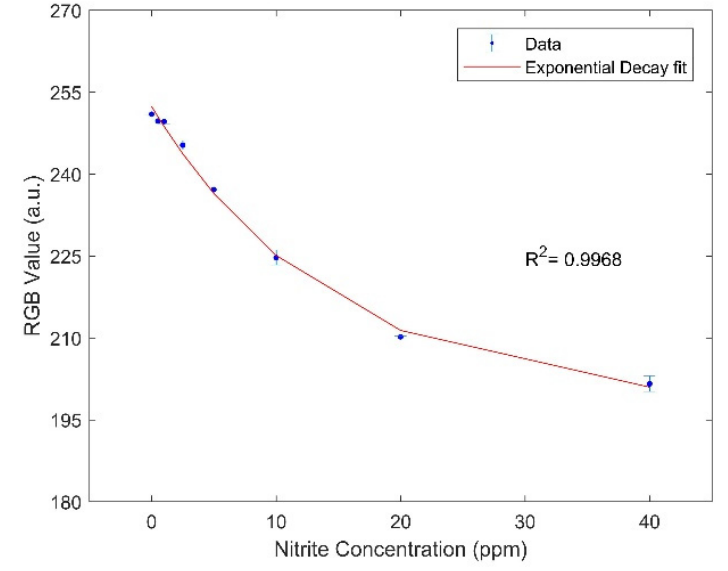

(a)

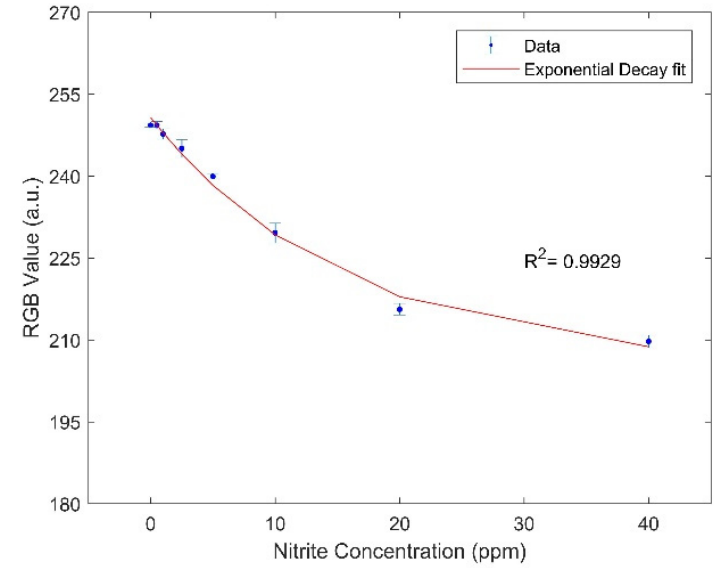

(b)

Figure 3. (a) An exponential decay calibration curve in the form $y=a \times \exp (-x / b)+c$, where $a=54.94, b=14.57$ and $c=197.4$ was established for nitrite after a reaction time of $5 \mathrm{~min}$. (b) An exponential decay calibration curve in the form $y=a \times \exp (-x / b)+c$, where $a=45.56, b=15.65$ and $c=205.2$ was established for nitrite after a reaction time of $1 \mathrm{~h}$. The error bars represent the standard deviation.

\subsection{Reduction Efficiency}

The reduction efficiency of vanadium (III) chloride was calculated using the data obtained in the above experiments used to calculate the LOD and LOQ for nitrate and nitrite. First, the results obtained from the nitrite experiment after $1 \mathrm{~h}$ were used to establish the calibration curve using the method outlined in Section 2.2. Then the results obtained from the nitrate experiment after $1 \mathrm{~h}$ were used to calculate the intersection of the measured result with the calibration established for nitrite using the symbolic toolbox. Table 2 gives the nitrate conversion efficiency calculated. As can be seen from the table, the conversion efficiency varies between almost $0 \%$ and $27 \%$. 
Table 2. Calculated nitrate conversion efficiency.

\begin{tabular}{ccc}
\hline Nitrate Concentration (ppm) & $\begin{array}{c}\text { Normalized Nitrite Concentration } \\
\text { Calculated (ppm) } \mathbf{1}^{\mathbf{1}}\end{array}$ & $\begin{array}{c}\text { Reduction Efficiency } \\
\mathbf{( \% )}\end{array}$ \\
\hline 0 & 0 & 0 \\
0.5 & 0.098 & $19.54 \pm 0.80$ \\
1 & 0.006 & $0.61 \pm 0.23$ \\
2.5 & 0.300 & $12 \pm 0.05$ \\
10 & 0.524 & $10.48 \pm 0.08$ \\
20 & 1.086 & $10.86 \pm 0.01$ \\
40 & 3.296 & $16.48 \pm 0.03$ \\
\hline
\end{tabular}

${ }^{1}$ This concentration is normalized by subtracting the intensity calculated for $0 \mathrm{ppm}$ from all other concentrations

\subsection{Discussion}

The limits of detection and quantification obtained for nitrate and nitrite in our analysis were much higher than those obtained by commercial dip strips using the Griess assay. This can be attributed to one or more of the following reasons: using the RGB mode in data analysis, not depositing enough reagent volume for reaction or using hydrochloric acid since it evaporates completely without producing acidic conditions when rewet. The reaction with the Griess assay should take place under acidic conditions [45].

A maximum reduction efficiency of $27 \%$ was obtained by vanadium (III) chloride. This is similar to the reduction efficiency obtained by Zinculose (27\%). However, this reduction efficiency was only obtained for a high nitrate concentration of $40 \mathrm{ppm}$, while lower concentrations resulted in a much lower reduction efficiency. This raises the question of repeatability and uniformity of vanadium (III) chloride nitrate reduction when used in paper-based devices.

Each of the two reducing agents, zinc microparticles and vanadium (III) chloride, has its own set of advantages and should be used in specific applications with an appropriate device design. Zinculose is a composite material that can be incorporated into any paperbased device. The zinc microparticles in Zinculose are held in place by the matrix, which allows the passage of more sample volume through the material and the reduction of more molecules as they pass through it. This allows for signal amplification as more molecules become available to be captured and detected. However, vanadium (III) chloride is not immobilized and would wash away in any lateral flow paper-based device design. Nitrate reduction using vanadium (III) chloride takes much longer than that by zinc microparticles. That is why commercial dip strips generally use zinc microparticles in the detection zone to reduce nitrate to nitrite before detection, Figure S5. Vanadium (III) chloride allows for the development of simple dip strips since the reducing reagent can be mixed with the detection chemistry and easily deposited in the detection zone. However, the limits of detection and quantification achieved by dip strips utilizing vanadium (III) chloride are not as good as those obtained in more intricate designs using zinc microparticles.

\section{Conclusions}

Paper-based microfluidic technology is a relatively new field of research that is gaining a lot of attention and is producing a lot of innovation. In this paper, we measured the performance of a dip strip utilizing vanadium (III) chloride to reduce nitrate before detection. We observed that vanadium (III) chloride has some drawbacks that make it impractical for use in paper-based devices meant for detecting nitrate. These include long reduction times required and low limits of detection and quantification obtained. Therefore, we recommend using zinc microparticles as the reducing agent for nitrate detection in paper-based devices. Future work will include developing a suitable lightbox, similar to [46], that emits green light for measuring nitrate and nitrite concentrations using paper-based devices utilizing the Griess assay in the field. 
Supplementary Materials: The following are available online at https: / www.mdpi.com/article/ 10.3390/CSAC2021-10459/s1, Figure S1. Dip strip used in experiments, Figure S2. Dip strip used in experiments after the solutions are dried on the detection zones, Figure S3. Color formed in the detection zone vs. nitrate or nitrite concentrations after several minutes, Figure S4. Color formed in the detection zone vs. nitrate or nitrite concentrations after $1 \mathrm{~h}$, Table S1. ImageJ analysis of nitrate detection zones after $10 \mathrm{~min}$. Test order was randomized, Table S2. ImageJ analysis of nitrate detection zones after $1 \mathrm{~h}$. Test order was randomized, Table S3. ImageJ analysis of nitrite detection zones after $5 \mathrm{~min}$. Test order was randomized, Table S4. ImageJ analysis of nitrite detection zones after $1 \mathrm{~h}$. Test order was randomized, Figure S5. Zinc microparticles observed using an electron scanning microscope with EDS analysis in the nitrate test fields of commercial dip strips (a) Quantofix 91313 (b) Quantofix 91351.

Author Contributions: Conceptualization, A.C., N.R., C.A. and M.F.; methodology, A.C.; software, A.C. and H.H.-B.; validation, A.C.; formal analysis, A.C.; investigation, A.C.; resources, C.A. and M.F.; data curation, A.C., C.A. and M.F.; writing-original draft preparation, A.C.; writing- review and editing, A.C., H.H.-B., N.R., C.A. and M.F.; visualization, A.C. and H.H.-B.; supervision, N.R., C.A. and M.F.; project administration, C.A. and M.F.; funding acquisition, C.A. and M.F. All authors have read and agreed to the published version of the manuscript.

Funding: This research was funded by the National Science Foundation under EPSCoR Cooperative Agreement \#OIA-1655221.

Institutional Review Board Statement: Not applicable.

Informed Consent Statement: Not applicable.

Data Availability Statement: Data is contained within the article or supplementary material. Additional data not presented in this article is available on request from the corresponding author.

Acknowledgments: The authors would like to acknowledge the support from the Rhode Island EPSCoR, which is funded by the National Science Foundation under Award \#OIA-1655221. The authors would also like to acknowledge the students, research scientists and visiting scholars at the Microfluidics Laboratory at the University of Rhode Island for their help and support. SEM and EDS data were acquired at the RI Consortium for Nanoscience and Nanotechnology, a URI College of Engineering core facility partially funded by the National Science Foundation EPSCoR, Cooperative Agreement \#OIA-1655221.

Conflicts of Interest: The authors declare no conflict of interest. The funders had no role in the design of the study; in the collection, analyses, or interpretation of data; in the writing of the manuscript; or in the decision to publish the results.

\section{References}

1. Bouhoun, M.; Blondeau, P.; Louafi, Y.; Andrade, F. A Paper-Based Potentiometric Platform for Determination of Water Hardness. Chemosensors 2021, 9, 96. [CrossRef]

2. Firdaus, M.L.; Aprian, A.; Meileza, N.; Hitsmi, M.; Elvia, R.; Rahmidar, L.; Khaydarov, R. Smartphone Coupled with a Paper-Based Colorimetric Device for Sensitive and Portable Mercury Ion Sensing. Chemosensors 2019, 7, 25. [CrossRef]

3. Oyewunmi, O.D.; Safiabadi-Tali, S.H.; Jahanshahi-Anbuhi, S. Dual-Modal Assay Kit for the Qualitative and Quantitative Determination of the Total Water Hardness Using a Permanent Marker Fabricated Microfluidic Paper-Based Analytical Device. Chemosensors 2020, 8, 97. [CrossRef]

4. Heidari-Bafroui, H.; Charbaji, A.; Anagnostopoulos, C.; Faghri, M. A Colorimetric Dip Strip Assay for Detection of Low Concentrations of Phosphate in Seawater. Sensors 2021, 21, 3125. [CrossRef] [PubMed]

5. Kim, H.; Hyung, J.; Noh, H. Rationalization of In-Situ Synthesized Plasmonic Paper for Colorimetric Detection of Glucose in Ocular Fluids. Chemosensors 2020, 8, 81. [CrossRef]

6. Islam, N.; Ahmed, I.; Anik, M.I.; Ferdous, S.; Khan, M.S. Developing Paper Based Diagnostic Technique to Detect Uric Acid in Urine. Front. Chem. 2018, 6, 496. [CrossRef] [PubMed]

7. Deroco, P.; Junior, D.W.; Kubota, L. Silver Inkjet-Printed Electrode on Paper for Electrochemical Sensing of Paraquat. Chemosensors 2021, 9, 61. [CrossRef]

8. Migliorini, F.L.; Dos Santos, D.M.; Soares, A.C.; Mattoso, L.H.C.; Oliveira, J.O.N.; Correa, D.S. Design of A Low-Cost and Disposable Paper-Based Immunosensor for the Rapid and Sensitive Detection of Aflatoxin B1. Chemosensors 2020, 8, 87. [CrossRef]

9. Teepoo, S.; Arsawiset, S.; Chanayota, P. One-Step Polylactic Acid Screen-Printing Microfluidic Paper-Based Analytical Device: Application for Simultaneous Detection of Nitrite and Nitrate in Food Samples. Chemosensors 2019, 7, 44. [CrossRef] 
10. Rosati, G.; Cunego, A.; Fracchetti, F.; Del Casale, A.; Scaramuzza, M.; De Toni, A.; Torriani, S.; Paccagnella, A. Inkjet Printed Interdigitated Biosensor for Easy and Rapid Detection of Bacteriophage Contamination: A Preliminary Study for Milk Processing Control Applications. Chemosensors 2019, 7, 8. [CrossRef]

11. Shriver-Lake, L.C.; Zabetakis, D.; Dressick, W.J.; Stenger, D.A.; Trammell, S.A. Paper-Based Electrochemical Detection of Chlorate. Sensors 2018, 18, 328. [CrossRef]

12. Zikulnig, J.; Khalifa, M.; Rauter, L.; Lammer, H.; Kosel, J. Low-Cost Inkjet-Printed Temperature Sensors on Paper Substrate for the Integration into Natural Fiber-Reinforced Lightweight Components. Chemosensors 2021, 9, 95. [CrossRef]

13. Vargas, A.; Gámez, F.; Roales, J.; Lopes-Costa, T.; Pedrosa, J. A Paper-Based Ultrasensitive Optical Sensor for the Selective Detection of $\mathrm{H}_{2} \mathrm{~S}$ Vapors. Chemosensors 2021, 9, 40. [CrossRef]

14. Li, Z. Nanoporous Silica-Dye Microspheres for Enhanced Colorimetric Detection of Cyclohexanone. Chemosensors 2018, 6, 34. [CrossRef]

15. Singh, A.T.; Lantigua, D.; Meka, A.; Taing, S.; Pandher, M.; Camci-Unal, G. Paper-Based Sensors: Emerging Themes and Applications. Sensors 2018, 18, 2838. [CrossRef]

16. Charbaji, A.; Heidari-Bafroui, H.; Anagnostopoulos, C.; Faghri, M. Literature Review of the Use of Zinc and Zinc Compounds in Paper-Based Microfluidic Devices. J. Miner. Mater. Charact. Eng. 2021, 9, 257-270. [CrossRef]

17. Charbaji, A.; Heidari-Bafroui, H.; Kumar, A.; Ragmani, N. Characterization and Modeling of Paper-based Bi-Material Actuator Cantilever; Application in Phosphate Detection. In Proceedings of the Innovations in Microfluidics and Single Cell Analysis, Boston, MA, USA, 18-19 March 2021.

18. Smith, W.; Rahmani, N.; Charbaji, A.; Lemos, N.; Anagnostopoulos, C.; Fanghri, M.; Hong, C. A Fluidically Controlled Bi-Material Actuator for Automation of Paper-Based Assays. In Proceedings of the International Symposium on Thermal Effects in Gas Flows in Microscale, Ettlingen, Germany, 24-25 October 2019.

19. Charbaji, A.; Heidari-Bafroui, H.; Anagnostopoulos, C.; Faghri, M. Sensitive Detection of Nitrate using a Paper-based Microfluidic Device. In Proceedings of the Innovations in Microfluidics and Single Cell Analysis, Boston, MA, USA, 17-18 August 2020.

20. Xu, Y.; Liu, M.; Kong, N.; Liu, J. Lab-on-paper micro- and nano-analytical devices: Fabrication, modification, detection and emerging applications. Microchim. Acta 2016, 183, 1521-1542. [CrossRef]

21. Fernandes, G.M.; Silva, W.R.; Barreto, D.N.; Lamarca, R.S.; Lima Gomes, P.C.F.; Flávio, D.S.; Petruci, J.; Batista, A.D. Novel approaches for colorimetric measurements in analytical chemistry-A review. Anal. Chim. Acta 2020, 1135, 187-203. [CrossRef]

22. Fernandes, S.C.; Walz, J.A.; Wilson, D.; Brooks, J.; Mace, C.R. Beyond Wicking: Expanding the Role of Patterned Paper as the Foundation for an Analytical Platform. Anal. Chem. 2017, 89, 5654-5664. [CrossRef] [PubMed]

23. Kasetsirikul, S.; Shiddiky, M.; Nguyen, N.-T. Wicking in Paper Strips under Consideration of Liquid Absorption Capacity. Chemosensors 2020, 8, 65. [CrossRef]

24. World Health Organization. Guidelines for Drinking-Water Quality, 4th Edition, Incorporating the 1st Addendum. 2017. Available online: https:/ / www.who.int/publications/i/item/9789241549950 (accessed on 22 October 2020).

25. US Geological Survey Nitrogen and Water. Available online: https://www.usgs.gov/special-topic/water-science-school/ science/nitrogen-and-water?qt-science_center_objects=0\#qt-science_center_objects (accessed on 22 October 2020).

26. US EPA Nutrient Pollution. Available online: https:/ / www.epa.gov/nutrientpollution/issue (accessed on 13 May 2021).

27. Silva, C.G.; Pereira, M.F.; Órfão, J.J.M.; Faria, J.L.; Soares, S. Catalytic and Photocatalytic Nitrate Reduction Over Pd-Cu Loaded Over Hybrid Materials of Multi-Walled Carbon Nanotubes and TiO2. Front. Chem. 2018, 6, 632. [CrossRef] [PubMed]

28. Gupta, S.; Gupta, R.C.; Gupta, A.B.; Eskiocak, S.; Rao, P.; Puttanna, K.; Singhvi, A. Pathophysiology of Nitrate Toxicity in Human and its Mitigation Measures. Bull. Reg. Assess React. Nitrogen 2010, 20, 1-78.

29. Ward, M.H.; Jones, R.R.; Brender, J.D.; De Kok, T.M.; Weyer, P.J.; Nolan, B.T.; Villanueva, C.M.; Van Breda, S.G. Drinking Water Nitrate and Human Health: An Updated Review. Int. J. Environ. Res. Public Health 2018, 15, 1557. [CrossRef] [PubMed]

30. Wierzbicka, E. Novel methods of nitrate and nitrite determination-A review. J. Elem. 2020, 25, 97-106. [CrossRef]

31. Kapoor, A.; Balasubramanian, S.; Muthamilselvi, P.; Vaishampayan, V.; Prabhakar, S. Lab-on-a-Chip Devices for Water Quality Monitoring. In Nanotechnology in the Life Sciences; Springer: Cham, Switzerland, 2020; pp. 455-469.

32. Charbaji, A.; Heidari-Bafroui, H.; Anagnostopoulos, C.; Faghri, M. A New Paper-Based Microfluidic Device for Improved Detection of Nitrate in Water. Sensors 2020, 21, 102. [CrossRef]

33. Jayawardane, B.M.; Wongwilai, W.; Grudpan, K.; Kolev, S.; Heaven, M.; Nash, D.M.; McKelvie, I. Evaluation and Application of a Paper-Based Device for the Determination of Reactive Phosphate in Soil Solution. J. Environ. Qual. 2014, 43, 1081-1085. [CrossRef]

34. Ratnarathorn, N.; Dungchai, W. Paper-based Analytical Device (PAD) for the Determination of Borax, Salicylic Acid, Nitrite, and Nitrate by Colorimetric Methods. J. Anal. Chem. 2020, 75, 487-494. [CrossRef]

35. Thongkam, T.; Hemavibool, K. An environmentally friendly microfluidic paper-based analytical device for simultaneous colorimetric detection of nitrite and nitrate in food products. Microchem. J. 2020, 159, 105412. [CrossRef]

36. Ferreira, F.T.S.M.; Mesquita, R.B.R.; Rangel, A.O.S.S. Novel microfluidic paper-based analytical devices ( $\mu$ PADs) for the determination of nitrate and nitrite in human saliva. Talanta 2020, 219, 121183. [CrossRef]

37. Wang, Q.-H.; Yu, L.-J.; Liu, Y.; Lin, L.; Lu, R.-G.; Zhu, J.-P.; He, L.; Lu, Z.-L. Methods for the detection and determination of nitrite and nitrate: A review. Talanta 2017, 165, 709-720. [CrossRef]

38. Mahmud, M.A.P.; Ejeian, F.; Azadi, S.; Myers, M.; Pejcic, B.; Abbassi, R.; Razmjou, A.; Asadnia, M. Recent progress in sensing nitrate, nitrite, phosphate, and ammonium in aquatic environment. Chemosphere 2020, 259, 127492. [CrossRef] 
39. Alahi, M.E.E.; Mukhopadhyay, S.C. Detection methods of nitrate in water: A review. Sens. Actuators A Phys. 2018, $280,210-221$. [CrossRef]

40. Jaywant, S.A.; Arif, K.M. A Comprehensive Review of Microfluidic Water Quality Monitoring Sensors. Sensors 2019, 19 , 4781. [CrossRef]

41. Ellis, P.S.; Shabani, A.M.H.; Gentle, B.S.; McKelvie, I.D. Field measurement of nitrate in marine and estuarine waters with a flow analysis system utilizing on-line zinc reduction. Talanta 2011, 84, 98-103. [CrossRef]

42. Charbaji, A.; Smith, W.; Anagnostopoulos, C.; Faghri, M. Zinculose: A new fibrous material with embedded zinc particles. Eng. Sci. Technol. Int. J. 2021, 24, 571-578. [CrossRef]

43. Charbaji, A.; Heidari-Bafroui, H.; Anagnostopoulos, C.; Faghri, M. A Practical System for the Quantitative Determination of Nitrate and Nitrite in the Field. In Proceedings of the 6th International Microfluidics Conference, Las Vegas, NV, USA, 26 March 2021.

44. James, N.; Miller, J.C. Statistics and Chemometrics for Analytical Chemistry, 5th ed.; Pearson: London, UK, 2005.

45. Weng, C.-H.; Chen, M.-Y.; Shen, C.-H.; Yang, R.-J. Colored wax-printed timers for two-dimensional and three-dimensional assays on paper-based devices. Biomicrofluidics 2014, 8, 066502. [CrossRef] [PubMed]

46. Heidari-Bafroui, H.; Ribeiro, B.; Charbaji, A.; Anagnostopoulos, C.; Faghri, M. Portable infrared lightbox for improving the detection limits of paper-based phosphate devices. Meas. J. Int. Meas. Conf. 2021, 173, 108607. [CrossRef] 